\title{
SERGANČIŲJŲ IŠEMINE ŠIRDIES LIGA IR ŠIRDIES NEPAKANKAMUMU FIZINIO AKTYVUMO YPATUMAI
}

\author{
Kristina Sauliūnaitè \\ Lietuvos sveikatos mokslų universitetas
}

\begin{abstract}
Raktažodžiai: treniruočių programos sergantiems išemine širdies liga, treniruočių programos sergantiems širdies nepakankamumu, reabilitacija.
\end{abstract}

\section{Santrauka \\ Tikslas - atrinkti ir išanalizuoti mokslinius straipsnius apie sergančiųjų išemine širdies liga ir širdies nepakan- kamumu fizinio aktyvumo ypatumus. Tyrimo metodas - sisteminè literatūros apžvalga. Mokslinių publikacijų paieška atlikta naudojantis PubMed paieškos sistema elektroninejje Medline duomenų bazeje. Atrinkti straips- niai parašyti anglų kalba. \\ Rezultatai. Sergantiesiems išemine širdies liga arba šir- dies nepakankamumu fizinio krūvio metu rekomenduo- jama stebèti, ar fizinis krūvis nesukelia nepageidaujamų reiškinių. Siekiant nustatyti pacientų klinikinị ịvertinimą, reikia atlikti fizinio krūvio tyrimus, echokardioskopiją bei diagnostinị ištyrimą. Svarbu ịvertinti, kuriai kardio- vaskulinès ligos rizikos grupei priskiriamas pacientas. Pagal individualius paciento fizinio pajègumo rodiklius parenkamas treniruočių intensyvumas. \\ Išvados. Sergantieji IŠL, kurių didelè fizinio krūvio su- keliamų nepageidaujamų reiškinių arba nuolatinès išemi- jos rizika, gali dalyvauti tokio intensyvumo laisvalaikio sporte, kuris būtų mažesnis už krūtinès anginos ir išemi- jos slenksčius. Kliniškai stabilūs ligoniai, sergantys ŠN su sumažèjusia KS išstūmio frakcija $(<40 \%)$, gali atlikti individualiai pritaikytus pratimus ir dalyvauti mažo ar vidutinio intensyvumo rekreaciniame sporte.}

\section{Ivadas}

Išeminè širdies liga (IŠL) pripažinta viena iš pagrindiniu mirtingumo priežasčių Vakarų šalyse [1]. IŠL serga 126 milijonai žmonių visame pasaulyje [2]. Tokị didelị IŠL paplitimą lemia mitybos ịpročiai, pasyvus gyvenimo būdas, nuolatinis stresas bei skubejjimas. Nustatyta, kad IŠL yra dažniausia širdies nepakankamumo (ŠN) priežastis [3]. ŠN serga apie 23 milijonai žmonių visame pasaulyje [4]. Moksliniais tyrimais įrodyta, kad fizinis aktyvumas pagerina sergančiųu IŠL ir
ŠN klinikinę ir funkcinę būklę bei gyvenimo kokybę, mažina mirtingumą $[5,6]$. Fizinis treniravimasis pasižymi teigiamu poveikiu širdies ir kraujagyslių sistemos ligu ( ̌́KL) rizikos veiksniams (dislipidemijai, antsvoriui, arterinei hipertenzijai) [5]. Kardiologinių pacientų fizinio treniravimo programos turi būti saugios, atitikti jų funkcinę būklę. Norint sudaryti efektyvią fizinio aktyvumo programą, reikia parinkti tinkamą treniravimosi intensyvumą, dažnį, trukmę bei metodiką. Šiuo tyrimu siekiama susisteminti naujausius duomenis iš elektronineje Medline duomenų bazeje rastų publikacijų apie fizinio treniravimo programas pacientams, sergantiems išemine širdies liga ir širdies nepakankamumu.

Tyrimo tikslas - atrinkti ir išanalizuoti mokslinius straipsnius apie sergančiujų išemine širdies liga ir širdies nepakankamumu fizinio aktyvumo ypatumus.

\section{Tyrimo medžiaga ir metodai}

Mokslinių publikacijų paieška atlikta naudojantis $\mathrm{Pu}-$ bMed paieškos sistema elektroninejje Medline duomenų bazejje. Atrinkti straipsniai parašyti anglų kalba.

\section{Tyrimo rezultatai}

Sergančiụjų IŠL fizinio treniravimo ypatumai. Pacientai, sergantys lètine išemine širdies liga, kuriems atlikus fizinio krūvio mèginị ir echokardioskopiją, nenustatoma širdies patologija, priskiriami nepageidaujamos organizmo reakcijos ị fizinị krūvị mažos rizikos grupei. Tokie asmenys gali dalyvauti didelio intensyvumo treniruotèse, varžybiniame sporte (1 lentelè) [7]. Didelio intensyvumo (jègos, mišrios, ištvermès) sportas (2 lentelè) turètų būti ribojamas vyresniems asmenims ( $>60$ metų), kuriems nustatytas lètinis išeminis sindromas. Šiuo atveju amžius yra papildomas stiprus prediktorius, skatinantis nepageidaujamų reiškinių atsiradimą fizinio krūvio metu, tačiau nèra nustatyta amžiaus apribojimų mažos rizikos pacientams dalyvauti nedidelio intensyvumo igūdžių sporte (2 lentelè) [5].

Asmenims, kuriems atsiranda krūtinès išemija, atlikus fizinio krūvio tyrimą, nepaisant adekvataus paskirto medikamentinio gydymo, turètų būti atliekama vainikinių ar- 
terijų angiografija. Pacientai, kurių didelè vainikinių arterijų (VA) pažeidimo rizika, gali grịžti ị didelio intensyvumo treniruotes arba varžybinį sportą praejjus 3-6 mèn. po sėkmingos VA revaskuliarizacijos (1 lentelè). Jeigu sergantiesiems miokardo išemija išlieka atlikus VA revaskuliarizaciją, varžybinis sportas draudžiamas. Išimtis - igūdžių sportas (golfas, stalo tenisas), saugus dalyvavimas laisvalaikio sporte, 2-3 k./sav., jei numatomos veiklos intensyvumas yra mažesnis nei išeminè riba [8].

Sergančiųjų širdies nepakankamumu (ك̌N) fizinio treniravimo ypatumai. Pacientams, sergantiems lètiniu ŠN, kontraindikuotina pradèti mankštas esant hipotenzijai, hipertenzijai ramybejje arba fizinio krūvio metu, besitęsiančiai miokardo išemijai, sunkiai ar nepakankamai gydomai plaučių ligai [9]. Asmenims, sergantiems ŠN $\mathrm{N}$, prieš paskiriant fizinị krūvị būtina atlikti kardiologinès būklès įvertinimą, nustatyti ŠN funkcinę klasę, ivvertinti natriuretinių peptidų koncentraciją kraujyje, atlikti echokardiografiją. Šiems pacientams svarbu atlikti spiroveloergometrijos tyrimą, vertinanti fizini pajègumą, fizinio krūvio sukeltas aritmijas bei hemodinamikos sutrikimus. Ligonių fizinio treniravimo programos turi būti saugios ir atitinkančios jų fizini aktyvumą. Fizinio krūvio intensyvumas parenkamas remiantis maksimaliu deguonies suvartojimo kiekiu $\left(\mathrm{VO}_{2}\right.$ peak) didžiausio ŠSD fizinio krūvio metu [10]. $\mathrm{VO}_{2}$ peak parodo paciento fizini pajègumą, jo didejimas tiesiogiai koreliuoja su geresne ligonio prognoze.

Aerobikos ar ištvermès pratimai rekomenduojami stabiliems pacientams (Niujorko širdies asociacija (NYHA) klasė I-III) dèl puikių rezultatų ir saugumo [11]. Dažniausiai vertinamas pratimų režimas yra vidutinio intensyvumo tęstiniai pratimai (angl. MCE - Moderate continuous exercise) [12]. Pacientams, priklausantiems III funkcinei klasei pagal NŠA, turètų būti palaikomas žemesnis pratimų intensyvumas, maksimalus de-
1 lentelè. Sergančiųjų IŠL klinikinis įvertinimas ir fizinio treniravimo rekomendacijos.

\begin{tabular}{|c|c|}
\hline \multicolumn{2}{|c|}{ Fizinio krūvio sukelta miokardo išemija } \\
\hline \multicolumn{2}{|c|}{ Invazinė VA angiografija } \\
\hline \multicolumn{2}{|c|}{ VA pažeidimo rizikos įvertinimas } \\
\hline & \\
\hline Maža rizika & Didelè rizika \\
\hline $\begin{array}{l}\text { Kairiojo skilvelio išstūmimo frakcija }>50 \% \text {; } \\
\text { Fizinis krūvis nesukelia aritmijų } \\
\text { Nėra išeminio širdies ploto skausmo }\end{array}$ & $\begin{array}{l}\text { Pagrindinès kairès VA stenozė }>50 \% \\
\text { Proksimalinės kairès priekinès nusileidžian- } \\
\text { čiosios VA stenozè }>50 \% \\
2 \text {-3 VA stenozė }>50 \% \\
\text { Vienos VA stenozè }>90 \%\end{array}$ \\
\hline$\downarrow$ & 1 \\
\hline Pacientas priklauso mažos rizikos grupei & $\begin{array}{l}\text { Pacientui turi būti atliekama revaskuliari- } \\
\text { zacija }\end{array}$ \\
\hline $\begin{array}{l}\text { Pacientas gali dalyvauti individualiai pritaiky- } \\
\text { tose intensyviose treniruotèse }\end{array}$ & $\begin{array}{l}\text { Kai revaskuliarizacija sėkminga, mažos } \\
\text { rizikos grupės pacientams leidžiama daly- } \\
\text { vauti individualiai pritaikytose intensyviose } \\
\text { treniruotėse } \\
\text { Kai po revaskuliarizacijos ir medikamen- } \\
\text { tinio gydymo išeminiai širdies skausmai } \\
\text { išlieka, rekomenduojama dalyvauti igūdžių } \\
\text { sporte, lengvo ar vidutinio intensyvumo } \\
\text { laisvalaikio sporte }\end{array}$ \\
\hline
\end{tabular}

2 lentelẻ. Sporto šakų rūšys ir jų intensyvumo lygis.

\begin{tabular}{|c|c|c|c|c|}
\hline \multirow{2}{*}{$\begin{array}{l}\text { Intensy- } \\
\text { vumo lygis }\end{array}$} & \multicolumn{4}{|c|}{ Sportas } \\
\hline & igūdžių & jẻgos & mišrus & ištvermės \\
\hline Mažas & $\begin{array}{l}\text { Golfas } \\
\text { Stalo tenisas } \\
\text { Boulingas }\end{array}$ & $\begin{array}{l}\text { Rutulio stūmimas } \\
\text { (rekreacinis) } \\
\text { Disko metimas (re- } \\
\text { kreacinis) } \\
\text { Kalnų slidinejjimas } \\
\text { (rekreacinis) }\end{array}$ & $\begin{array}{l}\text { Futbolas (pritai- } \\
\text { kytas) } \\
\text { Krepšinis (pri- } \\
\text { taikytas) }\end{array}$ & $\begin{array}{l}\text { Ilgo nuotolio vaikš- } \\
\text { čiojimas } \\
\text { Bejgimas } \\
\text { Plaukimas (rekrea- } \\
\text { cinis) }\end{array}$ \\
\hline Vidutinis & $\begin{array}{l}\text { Buriavimas } \\
\text { Plaukiojimas } \\
\text { jachta } \\
\text { Jodinejjimas }\end{array}$ & $\begin{array}{l}\text { Disko metimas } \\
\text { Rutulio stūmimas } \\
\text { Trumpų nuotolių } \\
\text { bėgimas } \\
\text { Dziudo ar karatė } \\
\text { Kalnų slidinèjimas }\end{array}$ & $\begin{array}{l}\text { Tinklinis } \\
\text { Lauko tenisas }\end{array}$ & $\begin{array}{l}\text { Greitas ejimas } \\
\text { Vidutinio ar ilgo nuo- } \\
\text { tolio bėgimas }\end{array}$ \\
\hline Didelis & - & $\begin{array}{l}\text { Boksas } \\
\text { Svorių kilnojimas } \\
\text { Imtynės }\end{array}$ & $\begin{array}{l}\text { Krepšinis (var- } \\
\text { žybinis) } \\
\text { Ledo ritulys } \\
\text { Futbolas (varžy- } \\
\text { binis) }\end{array}$ & $\begin{array}{l}\text { Triatlonas } \\
\text { Vidutinio ar ilgo nuo- } \\
\text { tolio plaukimas } \\
\text { Dviračių sportas } \\
\text { Ilgo nuotolio čiuoži- } \\
\text { mas } \\
\text { Irklavimas }\end{array}$ \\
\hline
\end{tabular}


guonies suvartojimo kiekis $\left(\mathrm{VO}_{2}\right.$ peak $)(<40 \%)$, atsižvelgiant i pasireiškiančius simptomus bei klinikinę būklę per pirmąsias 1-2 savaites. Toliau - laipsniškas intensyvumo didinimas iki 50-70 proc. $\left(\mathrm{VO}_{2}\right.$ peak) ir jeigu jis toleruojamas, galima didinti iki 85proc. $\left(\mathrm{VO}_{2}\right.$ peak), kaip pirminio tikslo [13].

Pastaruoju metu didelio intensyvumo intervalinių treniruočiu (HIIT) programos buvo siūlomos kaip alternatyvus pratimų variantas mažos rizikos pacientams [14]. Naujausia metaanalizè atskleidè, kad gerinant maksimalų deguonies suvartojimo kieki ( $\mathrm{VO}_{2}$ peak), didelio intensyvumo intervalo treniruotes (HIIT), palygintos su vidutinio intensyvumo tęstiniais pratimais (MCE), buvo pranašesnès sergantiesiems širdies nepakankamumu su sumažèjusia KS išstūmio frakcija $(<40 \%)$ trumpame laiko intervale [15]. Didelio intensyvumo intervalinių treniruočių (HITT) programos gali būti rekomenduojamos pirminiam mažos rizikos pacientų, turinčių širdies nepakankamumą, paruošimui, kai pacientai pageidauja grižti i didelio intensyvumo aerobikos ir mišraus tipo ištvermès sportą (2 lentelè).

Pasipriešinimo treniruotès gali papildyti, bet ne pakeisti aerobikos tipo treniruotes, nes jos atkuria prarastą skeleto raumenų masę ir dekondicionavimą, nesant per didelio streso širdžiai [16]. Treniruočių intensyvumas gali būti pasirinktinai nustatomas tokio pasipriešinimo lygiu, kai pacientas gali atlikti pratimą, kartodamas jị 10-15 kartų ties 15 balų padala Borgo skalèje (t.y. suvokiamas fizinis krūvis yra sunkus) [9]. Pacientams, kurių pakitusi skeleto raumenų funkcija ir yra raumenų išsekimo požymių, treniruočių pratimai pirmiausiai turètų būti orientuoti ị raumenų masès didinimą, naudojant pasipriešinimo programas, skiriamas mažos rizikos stabiliems pacientams, norintiems grįžti i jẻgos ir galingumo lavinimo sportą (pvz. svorių kilnojimą) (2 lentelè) [5].

C. Giuliano ir bendr. metaanalizès duomenimis, pasipriešinimo pratimai yra vienintelè intervencija, teikianti galimybę pacientams, turintiems širdies nepakankamumą su sumažėjusia KS išstūmio frakcija ir negalintiems dalyvauti aerobikos programoje, padidinti raumenų jègą, aerobinius pajègumus bei pagerinti gyvenimo kokybę [17]. Esant sunkiam širdies nepakankamumui arba, kai pacientai toleruoja labai nedidelį pratimų intensyvumą, pasipriešinimo pratimai gali būti saugiai taikomi treniruojant mažas raumenų grupes $[13,17]$.

\section{Išvados}

1. Sergantieji IŠL, kuriems fizinio krūvio keliama nepageidaujamų reiškinių rizika yra maža, gali dalyvauti didelio intensyvumo varžybinèje bei laisvalaikio sporto veikloje, išskyrus vyresnio amžiaus sportinininkus.

2. Sergantieji IŠL, kuriems fizinis krūvis kelia didelę nepageidaujamų reiškinių arba nuolatinès išemijos riziką, gali dalyvauti tokio intensyvumo laisvalaikio sporte, kuris būtų mažesnis už krūtinès anginos ir išemijos slenksčius.

3. Kliniškai stabilūs ligoniai, sergantys ŠN su sumažèjusia KS išstūmio frakcija $(<40 \%)$, gali atlikti individualiai pritaikytus pratimus ir dalyvauti mažo ar vidutinio intensyvumo rekreaciniame sporte.

4. Mažos rizikos pacientams, sergantiems ŠN, norintiems sportuoti didelio intensyvumo treniruotèse bei mišriose ištvermés sporto šakose, reabilitacinio gydymo procese gali būti taikomos didelio intensyvumo intervalinès treniruotès.

\section{Literatūra}

1. Sanchis-Gomar F, Perez-Quilis C, Leischik R, Lucia A. Epidemiology of coronary heart disease and acute coronary syndrome. Ann Transl Med 2016;4(13):256.

https://doi.org/10.21037/atm.2016.06.33

2. Khan MA, Hashim MJ, Mustafa H, et al. Global epidemiology of ischemic heart disease: results from the global burden of disease study. Cureus 2020;12(7): e9349.

https://doi.org/10.7759/cureus.9349

3. Bahit MC, Kochar A, Granger CB. Post-myocardial infarction heart failure. JACC Heart Fail 2018;6(3):179-186.

https://doi.org/10.1016/j.jchf.2017.09.015

4. Orso F, Fabbri G, Maggioni AP. Epidemiology of heart failure. Handb Exp Pharmacol 2017;(243):15-33

https://doi.org/10.1007/164_2016_74

5. Vanhees L, Geladas N, Hansen D, Kouidi E, Niebauer J, Reiner Z, Cornelissen V, Adamopoulos S, Prescott E, Börjesson M, Bjarnason-Wehrens B, Björnstad HH, Cohen-Solal A, Conraads V, Corrado D, De Sutter J, Doherty P, Doyle F, Dugmore D, Ellingsen Ø, Fagard R, Giada F, Gielen S, Hager A, Halle M, Heidbüchel H, Jegier A, Mazic S, McGee H, Mellwig KP, Mendes M, Mezzani A, Pattyn N, Pelliccia A, Piepoli M, Rauch B, Schmidt-Trucksäss A, Takken T, van Buuren F, Vanuzzo D. Importance of characteristics and modalities of physical activity and exercise in the management of cardiovascular health in individuals with cardiovascular risk factors: recommendations from the EACPR. Part II. Eur J Prev Cardiol 2012;19(5):1005-33.

https://doi.org/10.1177/1741826711430926

6. Vanhees L, Rauch B, Piepoli M, van Buuren F, Takken T, Börjesson M, Bjarnason-Wehrens B, Doherty P, Dugmore D, Halle M; Writing Group, EACPR. Importance of characteristics and modalities of physical activity and exercise in the management of cardiovascular health in individuals with cardiovascular disease (Part III). Eur J Prev Cardiol 2012;19(6):1333-56. https://doi.org/10.1177/2047487312437063

7. Newby DE, Adamson PD, Berry C, Boon NA, Dweck MR, Flather M, Forbes J, Hunter A, Lewis S, MacLean S, Mills NL, Norrie J, Roditi G, Shah ASV, Timmis AD, van Beek EJR, Williams MC. Coronary CT angiography and 5-year risk of myocardial infarction. N Engl J Med 2018;379(10):924-933. 
https://doi.org/10.1056/NEJMoa1805971

8. ESC Study Group of Sports Cardiology, Börjesson M, Assanelli D, Carré F, Dugmore D, Panhuyzen-Goedkoop NM, Seiler C, Senden J, Solberg EE. ESC study group of sports cardiology: recommendations for participation in leisure-time physical activity and competitive sports for patients with ischaemic heart disease. Eur J Cardiovasc Prev Rehabil 2006;13(2):137-49.

https://doi.org/10.1097/01.hjr.0000199494.46708.5a

9. Piepoli MF, Davos C, Francis DP, Coats AJ, ExTraMATCH Collaborative. Exercise training meta-analysis of trials in patients with chronic heart failure (ExTraMATCH). BMJ 2004;328(7433):189.

https://doi.org/10.1136/bmj.37938.645220.EE

10. Corrà U, Agostoni PG, Anker SD, Coats AJS, Crespo Leiro MG, de Boer RA, Harjola VP, Hill L, Lainscak M, Lund LH, Metra M, Ponikowski P, Riley J, Seferović PM, Piepoli MF. Role of cardiopulmonary exercise testing in clinical stratification in heart failure. A position paper from the Committee on Exercise Physiology and Training of the Heart Failure Association of the European Society of Cardiology. Eur J Heart Fail 2018;20(1):3-15.

https://doi.org/10.1002/ejhf.979

11. Long L, Mordi IR, Bridges C, Sagar VA, Davies EJ, Coats AJ, Dalal H, Rees K, Singh SJ, Taylor RS. Exercise-based cardiac rehabilitation for adults with heart failure. Cochrane Database Syst Rev 2019;1(1):CD003331.

https://doi.org/10.1002/14651858.CD003331.pub5

12. Gayda M, Ribeiro PA, Juneau M, Nigam A. Comparison of different forms of exercise training in patients with cardiac disease: where does high-intensity interval training fit? Can J Cardiol 2016 ;32(4):485-94.

https://doi.org/10.1016/j.cjca.2016.01.017

13. Piepoli MF, Conraads V, Corrà U, Dickstein K, Francis DP, Jaarsma T, McMurray J, Pieske B, Piotrowicz E, Schmid JP, Anker SD, Solal AC, Filippatos GS, Hoes AW, Gielen S, Giannuzzi P, Ponikowski PP. Exercise training in heart failure: from theory to practice. A consensus document of the Heart Failure Association and the European Association for Cardiovascular Prevention and Rehabilitation. Eur J Heart Fail 2011;13(4):347-57.

https://doi.org/10.1093/eurjhf/hfr017

14. Ellingsen Ø, Halle M, Conraads V, Støylen A, Dalen H, Delagardelle C, Larsen AI, Hole T, Mezzani A, Van Craenenbroeck EM, Videm V, Beckers P, Christle JW, Winzer E, Mangner N, Woitek F, Höllriegel R, Pressler A, Monk-Hansen T, Snoer M, Feiereisen P, Valborgland T, Kjekshus J, Hambrecht R, Gielen S, Karlsen T, Prescott E, Linke A, SMARTEX Heart Failure Study (Study of myocardial recovery after exercise training in heart failure) Group. High-intensity interval training in patients with heart failure with reduced ejection fraction. Circulation 2017;135(9):839-849.
https://doi.org/10.1161/CIRCULATIONAHA.116.022924

15. Gomes Neto M, Durães AR, Conceição LSR, Saquetto MB, Ellingsen $\varnothing$, Carvalho VO. High intensity interval training versus moderate intensity continuous training on exercise capacity and quality of life in patients with heart failure with reduced ejection fraction: a systematic review and meta-analysis. Int $\mathbf{J}$ Cardiol 2018;(261):134-141.

https://doi.org/10.1016/j.ijcard.2018.02.076

16. Cornelis J, Beckers P, Taeymans J, Vrints C, Vissers D. Comparing exercise training modalities in heart failure: a systematic review and meta-analysis. Int J Cardiol 2016;(221):867-76. https://doi.org/10.1016/j.ijcard.2016.07.105

17. Giuliano C, Karahalios A, Neil C, Allen J, Levinger I. The effects of resistance training on muscle strength, quality of life and aerobic capacity in patients with chronic heart failure - a meta-analysis. Int J Cardiol 2017;227:413-423.

https://doi.org/10.1016/j.ijcard.2016.11.023

\section{THE PECULIARITIES OF PHYSICAL ACTIVITY IN PATIENTS WITH CORONARY ARTERY DISEASE AND HEART FAILURE \\ K. Sauliūnaitè}

Keywords: coronary artery disease exercise programs, heart failure exercise programs, rehabilitation.

Summary

The aim is to select and analyze scientific articles on the peculiarities of physical activity in patients with coronary artery disease and heart failure. The research method is a systematic review of the literature. The search for scientific publications was performed using the PubMed search system in the electronic Medline database. The selected articles are written in English.

Results. In people with coronary artery disease (CAD) and heart failure it is recommended to monitor during exercise to ensure that exercise does not cause adverse events. In order to determine the clinical evaluation of patients, it is necessary to perform exercise tests, echocardiography and diagnostic examination. It is also important to assess which patient is at risk for cardiovascular disease. Training intensity is selected according to individual indicators of the patient's physical capacity.

Conclusions. Patients with CAD who are at high risk of developing exercise-induced adverse events or persistent ischemia may participate in recreational sports below the thresholds for angina and ischemia. Clinically stable heart failure patients with a reduced LV ejection fraction $(<40 \%)$ may perform individually tailored exercises and participate in low- to moderate-intensity recreational sports.

Correspondence to: kristinelisaul@gmail.com

Gauta 2021-04-14 